\title{
Associated factors of congenital heart disease among children in a rural health care setting in Sri Lanka
}

\author{
*W A A D De Silva ${ }^{1}$, I R Ragunathan ${ }^{2}$, R M C L Gunarathne ${ }^{3}$
}

Sri Lanka Journal of Child Health, 2021; 50(2): 203-208

\begin{abstract}
Introduction: Congenital heart disease (CHD) is the commonest congenital abnormality worldwide and carries a high mortality. To determine preventive strategies, information regarding the aetiological factors of CHD in Sri Lanka is essential.
\end{abstract}

Objectives: To determine the associated factors of CHD in a rural healthcare setting in Sri Lanka.

Method: A case-control study was carried out at Teaching Hospital Anuradhapura (THA) Sri Lanka, from July-December 2019 including 146 participants. Children under 5 years of age, who were diagnosed to have CHD following 2Dechocardiography, were included as cases. A community-based control selection was done including children who had normal 2Dechocardiography. A total of 73 cases and 73 controls were selected. The parents were interviewed using a structured questionnaire after obtaining informed written consent. Data were analysed using SPSS version 23.0. The odds ratio (OR) was used to determine the associated risk factors and the $95 \%$ confidence interval $(95 \% \mathrm{CI})$ was used to determine the statistical significance.

Results: Mothers who used non-steroidal antiinflammatory drugs (NSAIDs) showed risk associations with CHD (OR 2.02, 95\% CI=1.71 2.37). Anti-epileptic drug use during the first trimester (OR 2.02, 95\% CI=1.71-2.39), exposure to fire wood smoke (OR 3.39, 95\% CI=1.04-11.2) and paternal exposure to paints (OR 3.39, $95 \% \mathrm{CI}=$

${ }_{1}^{1}$ Acting Consultant Paediatrician, Base Hospital Puttalam, ${ }^{2}$ Consultant Paediatric Cardiologist, Teaching Hospital Anuradhapura, ${ }^{3}$ Medical Officer, Paediatric Cardiology Unit, Teaching Hospital Anuradhapura

*Correspondence: waad_desilva@yahoo.com

iD https://orcid.org/0000-0001-8621-7427

(Received on 16 March 2020: Accepted after revision on 01 July 2020)

The authors declare that there are no conflicts of interest

Personal funding was used for the project.

Open Access Article published under the Creative

Commons Attribution CC-BY (c) (i) License
1.04-11.2) emerged as significant risk factors of CHD.

Conclusions: In this rural healthcare setting in Sri Lanka, use of antiepileptic drugs, NSAIDs, exposure to firewood smoke and different types of paint during the antenatal period were significantly associated with CHD.

DOI: http://dx.doi.org/10.4038/sljch.v50i2.9555

(Key Words: Congenital heart disease, risk factors)

\section{Introduction}

Congenital heart disease (CHD) is the most common congenital abnormality identified around the world ${ }^{1}$. CHD constitutes $28 \%$ of all congenital defects ${ }^{2}$. Between 2500 to 3500 live births which occur in Sri Lanka are associated with $\mathrm{CHD}^{3,4}$. The management of major CHD imposes an economical challenge for a lower-middle income country such as Sri Lanka ${ }^{5}$. In addition, children with CHD and their families face many socio-economic and psychological challenges ${ }^{6}$.

Lack of information regarding the modifiable risk factors for CHD has become a drawback when designing preventive strategies. There are several definitive risk factors such as maternal rubella, phenylketonuria, pre-gestational diabetes, exposure to thalidomide and vitamin A congeners or retinoids. However, for other potential risk factors such as maternal and paternal illnesses, drug exposures and environmental exposures inadequate evidence exists $^{7,8,9}$. Individual variation of these identified risk factors and minimal availability of interventional options during the antenatal period are other identified problems. A health condition with such characteristics requires researches conducted at different settings and populations ${ }^{10}$.

North-Central Province is the biggest province in Sri Lanka and is ranked $8^{\text {th }}$ by the number of populations. Anuradhapura District is recognized as an area with an agricultural lifestyle, a low rainfall and relatively a poor socio-economic background. It is situated quite a distance away from the capital. Natural water is hard in nature and it is difficult to find clean drinking water. Wood and other fuel are used to generate energy rather than gas and electricity. Despite these deficiencies, the maternal and child health care service indicators of this area 
are compatible with other districts. Anuradhapura is the major city of the province and is the home for Teaching Hospital Anuradhapura (THA). A total of 3485 children with suspected CHD had presented to the paediatric cardiology clinic at THA in 2018 and out of them $1011(29 \%)$ were confirmed to have CHD. There is minimal amount of published data regarding the aetiological factors of CHD in Sri Lanka. Hence, there is a distinct requirement for periodical studies on this topic.

\section{Objectives}

To determine the antenatal and peri-conceptional associated factors of CHD among children born in a rural healthcare setting in Sri Lanka.

\section{Method}

This study was designed as a case-control study to achieve aforesaid objectives. Children less than 5 years of age and who had a confirmed cardiac abnormality on 2D-echocardiography were included as cases in this study. Cases were selected from the children who presented to the cardiology clinic at THA from July 2019 to December 2019.

Age and sex matched controls were selected from the same 'Grama-Niladhari' (GN) division from where the cases had been selected. The sample size for the single arm was calculated by using the equation $\mathrm{N}=\left[\mathrm{k} \times \mathrm{P}_{1}\left(1-\mathrm{P}_{1}\right)+\mathrm{P}_{2}\left(1-\mathrm{P}_{2}\right) /\left(\mathrm{P}_{1}-\mathrm{P}_{2}\right)^{2}\right]$ where $\mathrm{P}_{1}$ (expected proportion of variables in cases) and $\mathrm{P}_{2}$ (expected proportion of variables in controls) were taken as $80 \%$ and $95 \%$ respectively.

Alpha $(\alpha)$ and Beta $(\beta)$ were set at 0.05 and 0.2 respectively to calculate the ' $\mathrm{k}$ ' (constant which is a function of $\alpha$ and $\beta)^{11}$. Calculated sample size for a single arm of the study was 73 . Children who were diagnosed with chromosomal abnormalities and less than 37 weeks of gestation at birth were excluded from the study.

Definition of cases: Children who were diagnosed with a CHD by a consultant cardiologist through an echocardiogram.

Definition of controls: Children who were confirmed as not having a CHD through an echocardiogram. Selected controls were referred to a consultant cardiologist for 2D echocardiogram for exclusion of CHD.

Data were collected from the parents of the child by using an interviewer-administered questionnaire. Data on socio-demography, ante-natal, environmental and substance abuse were collected both subjectively and objectively by trained data collectors. Weights and heights of the mothers were measured and mothers with BMI more than 30 were grouped as obese. Environmental exposures of the parents were measured subjectively using 'yes' and 'no' scale. Data verification was done using antenatal records and other relevant medical documents available with parents.

Ethical Issues: Ethical clearance was obtained from the Ethical Review Committee of the Sri Lanka College of Paediatricians (No. SLCP/ ERC/ 2019/ 13). Written informed consent was obtained from the parents of the participating children

Statistical analysis: Descriptive statistics and calculation of odds ratios (OR) were done to describe the variables and to determine risk factors of CHD.

\section{Results}

All the participants were collectively included to describe the socio-demographic characteristics. They were then compared with the associated risk factors. Age of the children with CHD ranged from 1 to 58 months (Mean=5.53 months: $\mathrm{SD}=8.29$ months). Majority of children represented the age group below 2 years of age $(n=140: 95.8 \%)$ and were males $(n=76: 52.1 \%)$. Majority of the parents were Sinhalese. Most of them were educated only up to the GCE Ordinary Level or below (Table 1).

We studied the relationship of the recreational substances with the occurrence of CHD. Only one mother in the control group was reported as using alcohol and all the mothers in this study were nonsmokers. Mothers who were chewing betel were found to be equally divided between the cases and control groups. Among fathers, $45.2 \%$ were current users of alcohol among cases and controls. According to the study, fathers' alcohol usage, cigarette smoking and betel chewing habits were not associated with CHD (Table 2).

According to the table 3, obesity, pre-gestational diabetes mellitus and gestational diabetes mellitus were not significantly associated with CHD in this sample (Table 3).

One mother who had received anti-epileptics and two who had received NSAIDs were present and their offspring had CHD. Odds of developing CHD in offspring's of the mothers who had received antiepileptics or NSAIDS during the $1^{\text {st }}$ trimester were 2 times greater than those who had not. This finding was statistically significant at 5\% level. There was no significant association between erratic use of folic acid and a past history of miscarriages with the occurrence of CHD, though, the OR is greater than one (Tables 3 and 4).

Table 5 shows the environmental exposures of fathers. 
Table 1: Socio-demographic characteristics of parents of the children

\begin{tabular}{|c|c|c|c|}
\hline \multicolumn{2}{|c|}{ Parent } & Cases & Cases \\
\hline \multicolumn{2}{|c|}{ Mother } & 68 & $131(89.7)$ \\
\hline Ethnicity: Sinhalese & 63 & - & $02(01.3)$ \\
Tamil & 02 & 5 & $13(08.9)$ \\
Muslim & 08 & 46 & $92(63.1)$ \\
Education: Up to O/L & 49 & 26 & $47(32.2)$ \\
Up to A/L & 21 & 03 & $06(04.1)$ \\
Graduated & 03 & 19 & $44(30.1)$ \\
Age (years): $<25$ & 25 & 43 & $80(54.8)$ \\
$25-35$ & 37 & 11 & $22(15.1)$ \\
$>35$ & 11 & & $130(89.1)$ \\
\hline \multicolumn{2}{|c|}{ Father } & 67 & $02(01.3)$ \\
\hline Ethnicity: Sinhalese & 63 & - & $13(08.9)$ \\
Tamil & 02 & 05 & $01(0.68)$ \\
Muslim & 08 & 01 & $111(76.1)$ \\
Other & - & 55 & $27(18.5)$ \\
Up to A/L & 56 & 13 & $08(05.4)$ \\
\hline
\end{tabular}

Table 2: Usage of alcohol, smoking and betel chewing among fathers ( $n=73)$

\begin{tabular}{|c|c|c|c|c|}
\hline Substance & Cases & Controls & OR & 95\% CI \\
\hline Alcohol & 32 & 34 & 0.895 & $0.46-1.72$ \\
Yes & 41 & 39 & & \\
No & 15 & 19 & 0.735 & $0.34-1.59$ \\
\hline Smoking & 58 & 54 & & \\
Yes & 19 & 28 & 0.565 & $0.28-1.14$ \\
No & 54 & 45 & & \\
\hline Betel chewing & & & & \\
Yes & & & & \\
No & &
\end{tabular}

Table 3: Distribution of maternal nutritional and endocrinological conditions related to gestation (n=73)

\begin{tabular}{|l|c|c|c|c|}
\hline \multicolumn{1}{|c|}{ Condition } & Cases & Controls & OR & 95\% CI \\
\hline Obesity & 14 & 12 & 1.21 & $0.52-2.82$ \\
Yes & 59 & 61 & & \\
No & 03 & 01 & 3.09 & $0.32-30.5$ \\
\hline Pre-conceptional & 70 & 72 & & \\
diabetes mellitus & 19 & 28 & 0.565 & $0.28-1.14$ \\
Yes & 54 & 45 & & \\
No & & & & \\
\hline Gestational & & & & \\
diabetes mellitus & 18 & 13 & & $0.678-3.37$ \\
Yes & 55 & 60 & & \\
No & & & & \\
\hline Miscarriages & & & & \\
Yes & & & & \\
No & &
\end{tabular}


Table 4: Distribution of drug exposures of mothers during antenatal period $(n=73)$

\begin{tabular}{|l|c|c|c|c|}
\hline \multicolumn{1}{|c|}{ Environmental factor } & Cases & Controls & OR & $\mathbf{9 5 \%}$ CI \\
\hline Cooking with firewood & 69 & 61 & $\mathbf{3 . 3 9}$ & $\mathbf{1 . 0 4 - 1 1 . 2}$ \\
Yes & 04 & 12 & & \\
No & 01 & 04 & 0.24 & $0.062-2.20$ \\
\hline Proximity to factories & 72 & 69 & & \\
Yes & 21 & 15 & 1.56 & $0.73-3.34$ \\
No & 52 & 58 & & \\
\hline Exposure to vehicle emission & 13 & 22 & 0.52 & $0.23-1.09$ \\
Yes & 60 & 51 & & \\
No & 13 & 16 & 0.772 & $0.34-1.75$ \\
\hline Pipe borne water & 60 & 57 & & \\
Yes & & 59 & & \\
No & 55 & 14 & & 0.72 \\
\hline Domestic source of water & 18 & & & \\
Yes & & & & \\
No & & & & \\
\hline Filtered water & & & & \\
Yes & & & & \\
No & & & & \\
\hline
\end{tabular}

Table 5: Environmental exposures of fathers $(n=73)$

\begin{tabular}{|c|c|c|c|c|}
\hline Environmental factor & Cases & Controls & OR & $95 \% \mathrm{CI}$ \\
\hline $\begin{array}{l}\text { Exposure to motor painting } \\
\text { Yes } \\
\text { No }\end{array}$ & $\begin{array}{l}02 \\
71\end{array}$ & $\begin{array}{l}01 \\
72\end{array}$ & 2.02 & $0.18-22.8$ \\
\hline $\begin{array}{l}\text { Exposure to wood painting } \\
\text { Yes } \\
\text { No }\end{array}$ & $\begin{array}{l}04 \\
69\end{array}$ & $\begin{array}{l}03 \\
70\end{array}$ & 1.35 & 1.04-11.2 \\
\hline $\begin{array}{l}\text { Exposure to agrochemicals } \\
\text { Yes } \\
\text { No }\end{array}$ & $\begin{array}{l}20 \\
53\end{array}$ & $\begin{array}{l}25 \\
48\end{array}$ & 0.725 & $0.36-1.47$ \\
\hline $\begin{array}{l}\text { Proximity to factory } \\
\text { Yes } \\
\text { No }\end{array}$ & $\begin{array}{l}01 \\
72 \\
\end{array}$ & $\begin{array}{l}05 \\
68 \\
\end{array}$ & 0.189 & $0.02-1.69$ \\
\hline $\begin{array}{l}\text { Exposure to vehicle emission } \\
\text { Yes } \\
\text { No }\end{array}$ & $\begin{array}{l}23 \\
50 \\
\end{array}$ & $\begin{array}{l}17 \\
56 \\
\end{array}$ & 1.51 & $0.72-3.15$ \\
\hline $\begin{array}{l}\text { Pipe borne water } \\
\text { Yes } \\
\text { No }\end{array}$ & $\begin{array}{l}13 \\
60 \\
\end{array}$ & $\begin{array}{l}22 \\
51 \\
\end{array}$ & 0.52 & $0.23-1.09$ \\
\hline $\begin{array}{l}\text { Domestic source of water } \\
\text { Yes } \\
\text { No }\end{array}$ & $\begin{array}{l}13 \\
60 \\
\end{array}$ & $\begin{array}{l}16 \\
57 \\
\end{array}$ & 0.772 & $0.34-1.75$ \\
\hline $\begin{array}{l}\text { Filtered water } \\
\text { Yes } \\
\text { No }\end{array}$ & $\begin{array}{l}55 \\
18 \\
\end{array}$ & $\begin{array}{l}58 \\
15 \\
\end{array}$ & 0.79 & $0.36-1.72$ \\
\hline
\end{tabular}

\section{Discussion}

Studies on risk factors for CHD are in the form of a continuum, since emergence of new risk factors is always a possibility. Behaviour of risk factors could be different in a given context. Hence, the need of studying risk factors of CHD will never be saturated. This study was conducted to identify the risk factors of CHD in the context of a rural population in the dry zone of Sri Lanka.
We identified risk factors under the groupings of socio-demography, ante-natal, gestational, exposures to medications and chemicals and expert opinions. Most of the subjective data were verified by cross checking with valid documents. Environmental exposures were evaluated subjectively and considered as appropriate proxy measurements for this study according to the expert opinion $^{7,8,10,12,16}$. 
The Baltimore and Washington study states that exposure to pesticides and other agrochemicals directly affects the occurrence of $\mathrm{CHD}^{10}$. However, a contributory association with exposure to agrochemicals for CHD was not demonstrated in our study $(\mathrm{OR}=0.725,95 \% \mathrm{CI}=0.36-1.47)$. This could be due to the fewer incidences of CHD that were reported where the father was exposed to agrochemicals (Table 5). None of the mothers admitted exposure to agrochemicals during pregnancy.

Mills et $a l^{12}$ have reported that heavy alcohol intake by mothers during pregnancy is significantly associated with congenital malformations; however, only a single mother admitted use of alcohol during our study. Similarly, Alverson et $a l^{13}$ have reported that first trimester maternal cigarette smoking is a modest risk factor for select CHD phenotypes; however none of the mothers were smokers in this study. Accepted factors for CHD in developed countries cannot be applied directly to the rural settings in Sri Lanka. The odds ratios for smoking, alcohol consumption, betel chewing and exposure to agrochemicals by the father demonstrated that they had no statistically significant associations with CHD in this study (Tables 2 and 5), though these factors were identified as risk factors during previous studies ${ }^{2,7,8,14}$.

An observation of note is the risk association with CHD among mothers who had used firewood for domestic cooking and among parents who were exposed to vehicle emission, paint and solvents during their occupation. These findings demonstrate that ambient air pollution has a risk association with CHD. Gilboa et $a l^{15}$ have demonstrated a risk association between exposure of mothers to particulate and gaseous air pollutants during the first trimester of pregnancy and selected CHD.

Several studies have demonstrated the teratogenic effects of maternal obesity and pre-gestational diabetes $^{7,8}$. In our study there was no statistically significant association between maternal obesity, pre-gestational diabetes mellitus or gestational diabetes mellitus and CHD. The Atlanta birth defects case-control study demonstrated that periconceptional multivitamin use was associated with a reduced risk of $\mathrm{CHD}^{16}$. Therefore, by commencing folic acid intake from 3 months before pregnancy and continued use through the first trimester, incidence of both neural tube defects and that of CHD could be reduced. However, in our study there was no statistically significant risk association between folic acid intake and CHD.

The study findings indicate that the use of NSAIDs $(\mathrm{OR}=2.02: 95 \% \mathrm{CI}=1.72-2.39)$ and anti-epileptics
$(\mathrm{OR}=2.02: 95 \% \mathrm{CI}=1.72-2.38)$ during pregnancy is directly associated with the incidence of CHD. It is best to create an awareness regarding this matter among medical practitioners ${ }^{17}$. Water contamination may be an important source of human pesticide exposure. Animal studies and observational studies in humans have reported associations between CHD in offspring and pesticide exposure ${ }^{18}$. However, in our study drinking clean pipe borne, domestic or filtered water was not significantly associated with CHD.

This study was limited to a rural setting due to financial and time constraints. The study findings were deprived of sufficient information to include all the expected variables. This reduced the heterogeneity of the study sample and reduced the external validity of the study findings.

\section{Conclusions}

In this rural healthcare setting in Sri Lanka, use of antiepileptic drugs, NSAIDs, exposure to firewood smoke and different types of paint during the antenatal period were significantly associated with CHD.

\section{Acknowledgement}

We gratefully acknowledge the assistance provided by the hospital director and supportive staff of the Paediatric Cardiology Clinic at Teaching Hospital Anuradhapura.

\section{References}

1. Van Der Linde D, Konings EEM, Slager MA, Witsenburg M, Helbing WA, Takkenberg JJM, et al. Birth prevalence of congenital heart disease worldwide: A systematic review and meta-analysis. Journal of the American College of Cardiology 2011; 58(21):2241-7. https://doi.org/10.1016/j.jacc.2011.08.025 PMid: 22078432

2. Hoffman JIE, Kaplan S. The incidence of congenital heart disease. Journal of the American College of Cardiology 2002; 39(12): 1890-900.

https://doi.org/10.1016/S07351097(02)018 86-7

3. Wickramasinghe P, Lamabadusuriya SNS. Prospective study of congenital heart diseases in children. Ceylon Medical Journal 2000; 46(3):96-8.

https://doi.org/10.4038/cmj.v46i3.8133

PMid: 11732303

4. Ministry of Health Sri Lanka. Annual Health Bulletin 2015. 
5. Samarasinghe D. Paediatric cardiology in Sri Lanka: Yesterday, today and tomorrow. Sri Lanka Journal of Child Health 2014; 43(1):3-19.

https://doi.org/10.4038/sljch.v43i1.6655

6. Connor JA, Kline NE, Mott S, Harris SK, Jenkins KJ. The meaning of cost for families of children with congenital heart disease. Journal of Pediatric Health Care 2010; 24(5):318-25.

https://doi.org/10.1016/j.pedhc.2009.09.00 2

PMid: 20804952

7. Jenkins KJ, Correa A, Feinstein JA, Botto $\mathrm{L}$, Britt AE, Daniels SR, et al. Noninherited risk factors and congenital cardiovascular defects: current knowledge: a scientific statement from the American Heart Association Council on Cardiovascular Disease in the Young. Circulation 2007; 115(23):2995-3014. https://doi.org/10.1161/CIRCULATIONA HA.106.183216

PMid: 17519397

8. Cedergren MI, Selbing AJ, Källén BAJ. Risk factors for cardiovascular malformation: A study based on prospectively collected data. Scandinavian Journal of Work, Environment and Health 2002; 28(1): 12-7.

https://doi.org/10.5271/sjweh.641

PMid: 11873776

9. Liu S, Liu J, Tang J, Ji J, Chen J, Liu C. Environmental risk factors for congenital heart disease in the Shandong Peninsula, China: A hospital-based case- control study. Journal of Epidemiology 2009; 19(5): 122-30.

https://doi.org/10.2188/jea.JE20080039

PMid: 19398851 PMCid: PMC3924136

10. Loffredo CA, Silbergeld EK, Ferencz C, Zhang J. Association of transposition of the great arteries in infants with maternal exposures to herbicides and rodenticides. American Journal of Epidemiology 2001; 153(6):529-36.

https://doi.org/10.1093/aje/153.6.529

PMid: 11257060

11. Lwanga SK, Lemeshow S. Sample size determination in health studies: A practical manual. Geneva.: World Health Organization; 1991.
12. Alverson CJ, Strickland MJ, Gilboa SM, Correa A. Maternal smoking and congenital heart defects in the BaltimoreWashington Infant Study. Pediatrics 2011; 127(3):e647-53. https://doi.org/10.1542/peds.2010-1399 PMid: 21357347

13. Botto LD, Mulinare J, Erickson JD. Occurrence of congenital heart defects in relation to maternal multivitamin use. American Journal of Epidemiology 2000; 151(9):878-84.

https://doi.org/10.1093/oxfordjournals.aje. a010291

PMid: 10791560

14. Mills L, Graubard BI. Is moderate drinking during pregnancy associated with an increased risk for malformations? Pediatrics 1987; 80: 309-14.

15. Jiayu Peng, Zhuo Meng, Shuang Zhou, Yue Zhou, Yujian Wu, Quingjie Wang, et al. The non-genetic paternal factors for congenital heart defects: A systematic review and meta analysis. Clinical Cardiology 2019; 42:684-91

https://doi.org/10.1002/clc.23194

PMid: 31073996 PMCid: PMC6605632

16. Gilboa SM, Mendola P, Olshan AF, Langlois PH, Savitz DA, Loomis D, et al. Relation between ambient air quality and selected birth defects, Seven County Study, Texas, 1997-2000. American Journal of Epidemiology 2005; 162:238-52. https://doi.org/10.1093/aje/kwi189 PMid: 15987727

17. Bracken MB, Holford TR. Exposure to prescribed drugs in pregnancy and association with congenital malformations. Obstetrics and Gynecology 1981; 58:33644.

18. Goldberg SJ, Lebowitz MD, Graver EJ, Hicks S. An association of human congenital cardiac malformatons and drinking water contaminants. Journal of the American College of Cardiology 1990; 16: 155-64. https://doi.org/10.1016/07351097(90)9047 3-3 